\title{
Primary School Principals' Experiences with Smartphone Apps
}

\author{
Rahman Çakır ${ }^{1}$, Sayım Aktay ${ }^{2}$ \\ ${ }^{1}$ Educational Faculty, Giresun University, Giresun, Turkey \\ ${ }^{2}$ Educational Faculty, Muğla Sttkı Koçman University, Muğla, Turkey \\ Correspondence: Sayım Aktay, Educational Faculty, Giresun University, Giresun, Turkey.
}

Received: September 12, 2016

Accepted: October 8, 2016

Online Published: October 19, 2016

doi:10.11114/jets.v4i12.1869

URL: http://dx.doi.org/10.11114/jets.v4i12.1869

\begin{abstract}
Smartphones are not just pieces of hardware, they at same time also dip into software features such as communication systems. The aim of this study is to examine primary school principals' experiences with smart phone applications. Shedding light on this subject means that this research is qualitative. Criterion sampling has been intentionally selected for use in this research. The criteria taken into consideration include that the research participants must be primary school principals, and that the participants use smart phones with Android-based communication systems and Android-based apps. Participants voluntarily used the application that was developed by the researchers over a one-month period during the 2015-2016 Spring teaching term. The vast majority of primary school principals who use smartphones found smartphone apps to be very beneficial. On one hand, primary school principals experienced a number of positive encounters with smartphone apps, including instant accessibility, quick access to information, the steer away from memorizing information, access to contemporary information, time saved in terms of decision making, as well as refrain from making errors. On the other hand, principals also experienced several negative encounters, including confronting inaccessibility, addiction, and making lazy education.
\end{abstract}

Keywords: primary school principals, smartphone apps, smartphone

\section{Introduction}

Present-day technology and technological devices are ever rapidly and constantly advancing, especially when it comes to bells and whistles features. As the large and clunky computers of yesteryear disappear, much smaller and much faster performing devices are growing in number. The phones of the past, which were used solely for basic functional communication, have been changed and advanced through computerization. Today's cell phones, when compared with their predecessors, are very different both in terms of hardware and in of software. This hybridization of cell phones with the computer features has thus coined the term "smartphone." PC Magazine (PC Magazine, 2016) defines smartphones as being advanced technological devices that can be used like computers, including having features such as web access, music, videos, and GPS navigation, etc.

Smartphones are not only just pieces hardware; they at the same time have software, i.e. communication systems software. Smartphones also make use of programs known as "applications" or "apps". With this in mind, a market as emerged for the development of apps specially-designed for smartphones. Thus, users are able to directly access apps for their phone as well as are able to examine and filter through apps according to their needs, as well as easily and install use apps according to their wants. According to Statistsa (2016), some 2.2 million Android apps, 2 million iOS apps, 699 million Windows apps, and 234.5 thousand BlackBerry apps exist on the market as of 2016.

Today's smartphones can, in addition having applications that enrich marketing services (Kocak, Dilek, and Saniloz, 2013) and serving as individual tracking systems i.e. to lower losses (Batmaz, Çelik, Bayılmış, and Kırbaş, 2015), also give value to mobile-based educational apps (Yüksel, Çankaya, Yalçınkaya, and Ateş, 2016). Pattern, Sanchez and Tangey (2016) noted that smart phones in education can be used as a basic method resource for exam preparation, not taking, and language study, interactive examinations, simulation games, data acquisition, location awareness, and instant messaging, etc. When studies involving (the use of) smart phone apps within an educational context are examined, what is encountered deals with primary school teachers using game apps as a homework tool (Neuneier and Lochmann, 2015), health apps that are easily accessible to school nurses and students (Penfold, 2013), atlas apps that easify the teaching of and students study of geography (Nunez, 2013), and educational apps that all-encompassingly 
strengthens the relationship between schools and guardians (PR Newswire, 2013).

The aim of this research is to study primary school principals' experiences with smartphones. Within this, the following sub-aims have been examined in order to provide focus:

- What do primary school principals think overall about the use of smart phones in education?

- What positive experiences with smart phone apps do primary school principals have?

- What negative experiences with smart phone apps do primary school principals have?

- Within the context of these experiences, what are their suggestions?

\section{Method}

\subsection{Research Model}

This study's research is qualitative and aims to highlight primary school principals' experiences with smart phone apps. Qualitative research methodology was chosen in order to examine these overall experiences in much greater depth.

\subsection{Research Participants}

Criterion sampling was the method of research used. The criteria taken into consideration include that the research participants must be primary school principals, and that the participants use smart phones with Android-based communication systems and Android-based apps. Principals who either don't use smart phones or who use non-Android-based smart phones where not considered for this study. Personal characteristics about the participants are presented in Table 1:

Table 1. Research participants' personal characteristics

\begin{tabular}{ll}
\hline Variable & $\mathrm{N}$ \\
\hline Gender & 1 \\
Female & 9 \\
Male & \\
Years of experience as in administration & 3 \\
10 years or under & 4 \\
11 - 20 years & 3 \\
21 plus years & \\
Career experience (overall) & 5 \\
20 years or under & 5 \\
21 plus years & \\
Smart phone use (number of years) & 1 \\
2 years & 4 \\
3 years & 1 \\
4 years & 4 \\
5 years & 1 \\
Finds regulations to be beneficial & 2 \\
Some benefit & 7 \\
Great benefit & \\
\hline
\end{tabular}

As can be seen in Table 1, there were a total of 10 participants - one of which was female, the other nine male. Three people had 10 years' and below of administration experience, four people had between 11 and 20 years of experience, and three people at 21 plus years of experience in administration. Five people had been working for 20 years or under in their career, five people had been working for some 21 plus years. As for how many years principals had been using smart phones, one person had been doing so for 2 years, four people for 3 years, one person for 4 years, and for people for five years. As for the implementation of regulation, one person found it to be of little benefit, two people found it to be of some benefit, and seven people found it to be of great benefit.

\subsection{The Development of the Smart Phone App}

With the goal of developing of a smart phone app, firstly, what resources principals felt were needed in terms of laws, 
codes, implementations, and guidelines, etc. was researched and gathered. During this period, Internet images were found, and resources on current legislation that were not available in text searches were converted into text format and then made searchable. Using this information, and with the necessary general guidelines, laws, codes, and implementations in place, this information was converted into an internally searchable and easy-to-access as needed Android application.

Then, this develop Android app was uploaded into the Google Play Android market and presented as easy to access and easy to use. It was ensured that the developed Android app be made small in size, thus an 821 KB-sized app that took up very little phone space. Also, the app could be used on any smartphone with a minimum of an Android 2.3 platform, again small in size. A sample screenshot of the developed app is displayed in Figure 1.

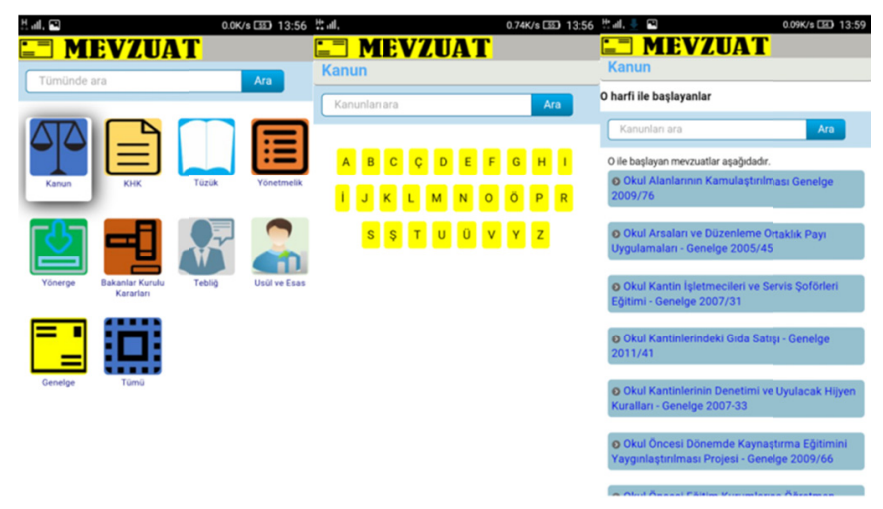

Figure 1. A sample screenshot of the "Legislation" Android App

The android app was introduced and made available via a workshop to principals working in primary schools in a provinces central district in Turkey. Participants voluntarily used the application over a one-month period during the 2015 - 2016 Spring teaching term. Finally, primary school principals' experiences using the app were examined.

\subsection{Data collection Tools}

An open-ended survey was developed and used as a data collection tool. An open-ended survey was preferred for reasons such as that the questions were not dense for principals and that the survey was completely accessible for the participants. On the open-ended survey form provided to the principals, the questions given measured positive and negative smartphone app experiences, as well suggestions. Then, the completed surveys were transmitted.

\subsection{Data Analysis and Interpretation}

Descriptive analysis was used to analyze the data based on the data obtained from open-ended survey. Descriptive analysis analyzes and interprets the obtained data within the frame of the topic in question. A qualitative data analysis program NVivo proved to be of benefit in analyzing the interview data. The NVivo program packages" "free" and "tree" nodes provide a clearer and more intelligible means of presenting what is being analyzed.

Finally, the next phase involved the collected data being separately analyzed both by the researches and by an independent expert. The results of both analyses revealed favorable themes. Within the context of this, differences of opinion between the researchers and the independent expert were identified. The researchers and expert either identified the same theme or assumed no common theme whatsoever. If there were thematic differences between the researchers and independent expert, this was also identified as being a difference of opinion. Within the context of common themes confirmed by the researchers and independent expert, Miles and Huberman's (1994) suggested formula of (Credibility = Agreement / Agreement + Disagreement) x 100) was used, with 87\% reliability. As the credibility number was larger than .70 , the themes that arose were assumed to be reliable.

\section{Results}

In the results and commentary section, the results and commentary of the research's goals concerning principals' experiences with smartphone apps in education have been presented systematically.

\subsection{Primary School Principals' General Thoughts on the Subject of Smartphone Use in Education}

Firstly, within the context of the research, primary school principals' overall general opinions on the subject of smartphone app use in education were examined. These views are shown in Figure 2. 


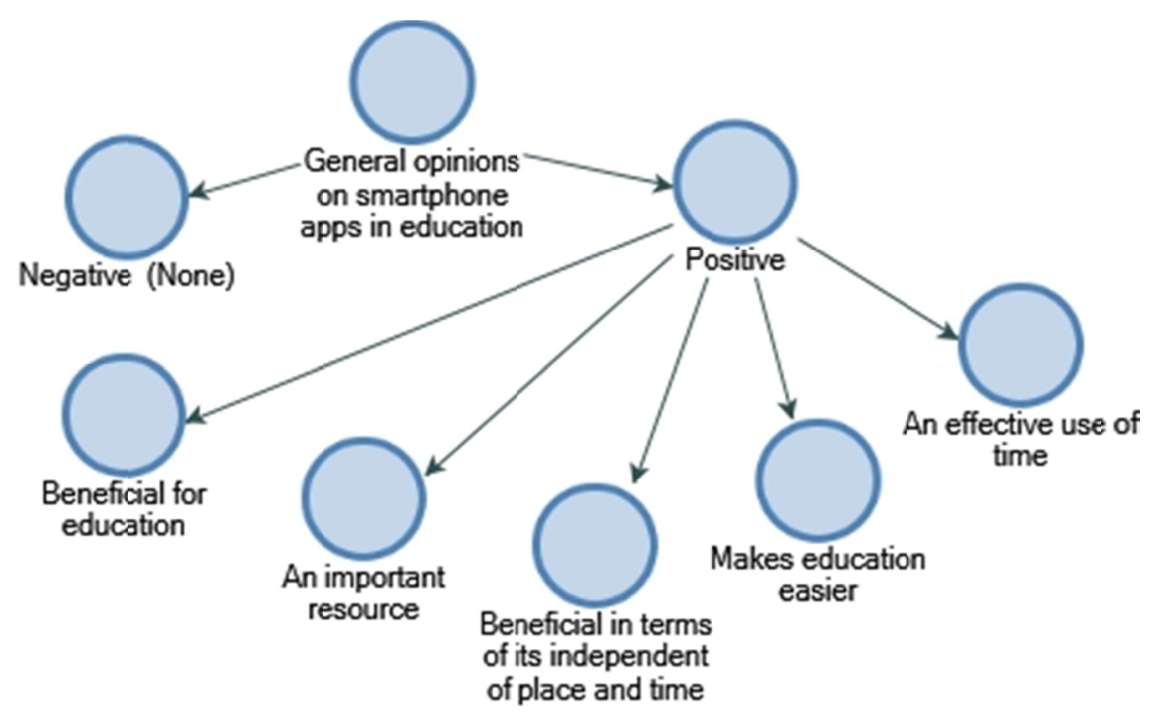

Figure 2. Primary school principals' opinions on the subject of smartphone app use in education

As can be seen in Figure 2, primary school principals hold no negative opinions about the use of smartphone apps in education. According to the principals, using smartphone apps present beneficial ease independent of time and location, ease of use in education, and advantages such as the chance for effective use of time.

Of the positive aspects principals felt with regards to smartphone app use in education, one was the benefit of independence from time and location, as broadly expressed in the opinion "Education-purposed smartphone app use presents a beneficial opportunity when not tied to the concepts of time and place". The chance for effective use of time was also provided, as broadly mentioned in "Some (smartphone) apps prove beneficial in terms of effective and productive use of time."

One principal expressed briefly that accessibility is the most important factor. Another, on the subject smartphone apps' use to education noted "I use smartphone apps for education in everything. I find it useful. Staying informed and not keeping ones distance from advancement is necessary in an ever advancing and changing world."

\subsection{Primary School Principals' Positive Experiences with the Use of Smartphone Apps}

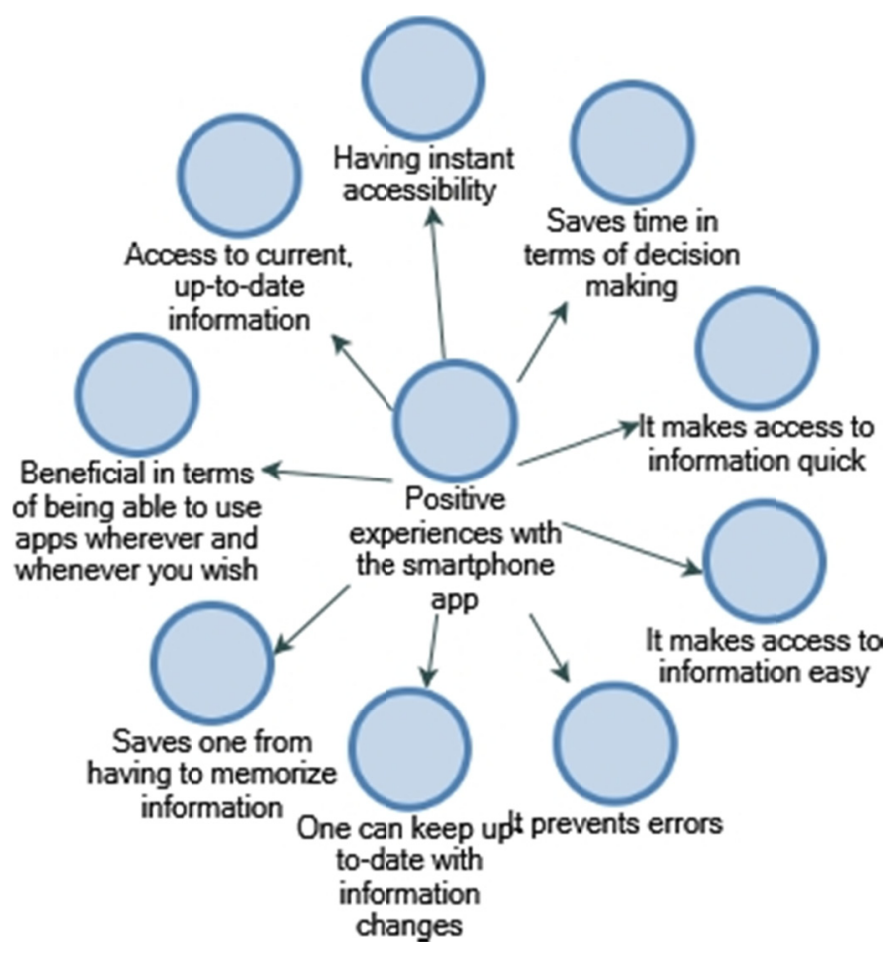

Figure 3. Primary school principals' positive experiences with smartphone apps 
When the principals participating in the research's positive experiences were examined, a number of optimistic opinions were expressed. Instant accessibility, time saved in terms of decision making, ease and speed of access to information, potential desired benefits in terms of place and time, and a refrain from errors made are some of the favourable things that were experienced by school principals.

Primary school principals' viewed the ease of access to information as either "Researching legislation needs to be just a click away for researchers", or, as "A good, sound application that makes accessibility to legislation easy when encountered". As for quick access to information, both "Access to desired information in the shortest amount of time possible", and "The legislation is (meant to) be accessed quickly. It must be alphabetical in order to be of better use" were cited.

A refrain from errors was another one of the positive experiences had by primary school principals. One principal on this subject stated that, "I found this app to be beneficial in that it was created bug-free". Another principal, on being able to keep track of changes, expressed: "To closely keep track of all changes in legislation". Another principal on keeping information from having to be memorized expressed that "having information on an as-needed basis instead of having to memorize all legislative information is beneficial."

Another positive experience was being able to benefit from desired time and place. One principal stated "being able to access legislative information whenever and from wherever I want." Then, on the matter of being able to access up-to-date current information, principals were of the opinion that "ensuring that current information on legislation be made accessible from anywhere." Finally, when it came to how smartphone app use saves time in decision-making, principals mentioned either that "decision making when keeping the system continuously updated", or that "using a legislation app in education saves principals time".

\subsection{Primary School Principals’ Negative Experiences with the Use of Smartphone Apps}

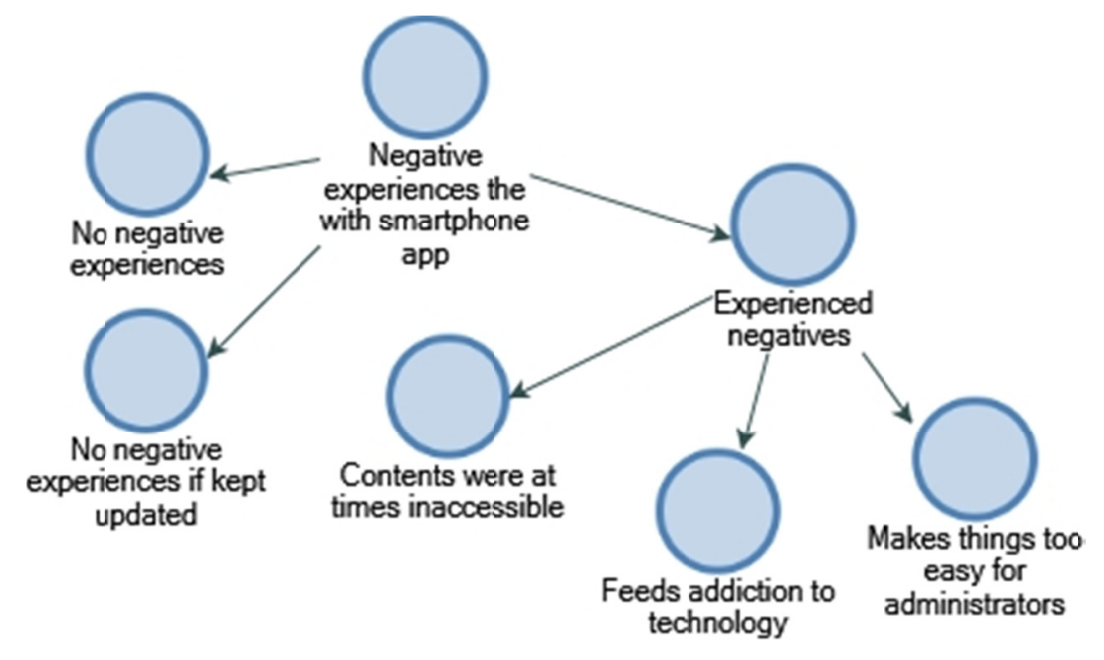

Figure 4. Primary school principals' negative experiences with smartphone apps

When principals were asked about their negative experiences with smartphone app use, some expressed there being no negative aspects, some expressed there being no negatives if kept up to date, and some appeared to have a number of negative experiences. These, possibly due to being unable to access the table of contents, feeding into addiction, and making administrators lazy.

On the matter of inaccessibility, principals responded with "None of the files opened". On feeding addiction, responses included "[But] I'm against addiction", "The negative aspects are enabling addiction", and "It causes addiction". As for principals' responses regarding [the app] making administrators lazy, "It potentially makes things a little too easy for the users. It can potentially blind people's culture of research." 


\subsection{Primary School Principals'Suggestions on the Subject of Smartphone App Use Based on Their Experiences}

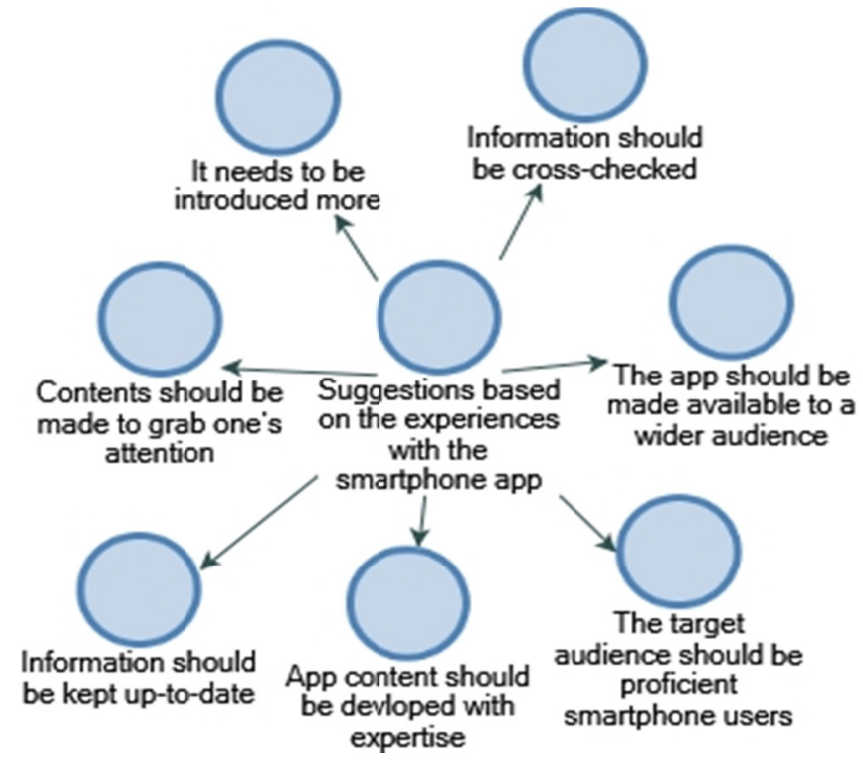

Figure 5. Primary school principals' suggestions based on their smartphone app usage experience

Primary school principals' experiences in using the smartphone app has given rise to a number of suggestions. Some of these suggestions include the need to monitor information, making the app accessible to a broader range of people, keeping information up-to-date, delivering the table of contents effectively, and doing more in terms of advertisement.

On the subject of keeping information current, principals cited that "Out-of-date laws, regulations, notices, and other legislation has to be thrown out, and continuously kept up-to-date", as well as emphasized that "more in the way of advertising could be done". Furthermore, one principal was of the opinion and thus suggested that "One first needs to be good smartphone user". Another expressed that "This app needs to reach a broader audience, especially introducing it to Faculty of Education students", respectively being under the opinion that the app needs to be more widely circulated.

Moreover, principals expressed that the table of contents needs to be put together by an expert, noting that "Apps should be prepared by specialists". Alongside this, one principal suggested that the information needs to be monitored, stating that "As the information exists in cyber space that is sometimes uncorroborated and that much of the information may be lack citation, this thus can give users false information. It should be monitored."

\section{Discussion}

Primary school principals who used the smartphone app have by and large found it to be very beneficial. No principal was of the opinion that the use of smartphones for educational purposes was a bad idea. They were of many a positive opinion such as that it made education easier, it ensured easiness due to its independence from time and location, and that it ensured an effective use of time.

Primary school principals on the subject of the app itself confirmed having a number of positive experiences including instant accessibility, quick access to information, the push away from having to memorize information, access to up-to-date information, saving time on decision-making, as well a refrain from making errors. With regards to the latter two experiences, primary school supervisors felt that advancing vocational aptitude from a portability perspective was important. These positive experiences correlate with findings made by Ly, Asplund and Andersson (2014) involving Swedish middle school principals in which smartphone apps were shown to have positive effects during stressful situations.

On the other hand, several negative experiences such as potential conflicts over being unable to access the table of contents, the potential for addiction, and lazifying education were also encountered. Within this context, negative experiences such as addiction and the lazifying of education were seen as being psychological. These findings correspond with similar findings by Rodrigues (2011) involving certain South African firm administrators having to have several rules put in place in order to effectively use their smartphones during work as well as correct their shortfall in personal agency.

Based on what was drawn from primary school principals' experiences with smartphone apps, suggestions thereof thus include that special attention should be given to the table of contents, information be kept current and monitored, and that the app be marketed to a broader audience. Below are the established suggestions based on the findings of this research. 
- More smartphone applications should be developed for primary school principals/administrators.

- Developed smartphone apps should have up-to-date information, instant accessibility, and be given prominence.

- Developed smartphone apps should be introduced to primary school principals.

- Smartphone apps should be developed for various facets of education.

\section{References}

Batmaz, B., Çelik, Z., Bayılmış, C., \& Kırbaş, İ. (2015). Akıllı telefon temelli birey takip sistemi. Sakarya Üniversitesi Fen Bilimleri Enstitüsü Dergisi, 19(1), 75-82.

Ly, K. H., Asplund, K., \& Andersson, G. (2011). Stress management for middle managers via an acceptance and commitment-based smartphone application: A randomized controlled trial. 1(3), 95-101.

Neuneier, S., \& Lochmann, G. (2015). A Teacher-Customizable Smartphone-Game for Primary School Teaching. Proceedings of the Multidisciplinary Academic Conference, 1-7.

Nunez, J. J. R. (2013). Smartphone-Based School Atlases? Cartographica, 48(2), $126-133$. http://dx.doi.org/10.3138/carto.48.2.1842

Patten, B., Arnedillo, S. I., \& Tangney, B. (2006). Designing collaborative, constructionist and contextual applications for handheld devices. Computers in Education, 46, 294-308. http://dx.doi.org/10.1016/j.compedu.2005.11.011

PC Magazine. (2016). Smartphone Definition from PC Magazine Encyclopedia. http://www.pcmag.com/encyclopedia/term/51537/smartphone adresinden 02.06.2016 tarihinde alınmıştır

Penhold, J. (2013). Students access school nurses through smartphone apps. Primary Health Care, 23(7), 8-10. http://dx.doi.org/10.7748/phc2013.09.23.7.8.s9

PR Newswire. (2013). Free Customizable Smartphone App Helps Schools Deliver Important Information to Students and Parents. PR Newswire US.

Rodrigues, A. (2011). The perceived impacts of smartphone use on the performance of senior managers in South African firms. Yayımlanmamış Yüksek Lisans Tezi. The Graduate School of Business, University of Cape Town.

Şanlıöz, H. K., Dilek, S. E., \& Koçak, N. (2013). Değişen Dünya, Dönüşen Pazarlama: Türkiye Turizm Sektöründen Öncü Bir Mobil Uygulama Örneği. Anatolia: Turizm Araştırmaları Dergisi, 24(2), 250-260.

Statista. (2016). Number of apps available in leading app stores as of June 2016. http:/www.statista.com/statistics/276623/number-of-apps-available-in-leading-app-stores/adresinden20.06.2016tar ihinde alınmıştır

Yüksel, A. S., Çankaya, İ. A., Yalçınkaya, M. A., \& Ateş, N. (2016). Mobil tabanlı optik form değerlendirme sistemi. Pamukkale Üniversitesi Mühendislik Bilimleri Dergisi, 22(2), 94-99.

\section{$(\mathrm{cc}) \mathrm{Br}$}

This work is licensed under a Creative Commons Attribution 3.0 License. 